\title{
Thermal structure of intense convective clouds derived from GPS radio occultations
}

\author{
R. Biondi ${ }^{1}$, W. J. Randel ${ }^{2}$, S.-P. Ho ${ }^{3}$, T. Neubert ${ }^{1}$, and S. Syndergaard ${ }^{4}$ \\ ${ }^{1}$ DTU Space, National Space Institute, Copenhagen, Denmark \\ ${ }^{2}$ NCAR, National Center for Atmospheric Research, Boulder CO, USA \\ ${ }^{3}$ NCAR-UCAR/COSMIC, Boulder CO, USA \\ ${ }^{4}$ DMI, Danish Meteorological Institute, Copenhagen, Denmark
}

Correspondence to: R. Biondi (ribi@ space.dtu.dk)

Received: 19 September 2011 - Published in Atmos. Chem. Phys. Discuss.: 27 October 201

Revised: 31 March 2012 - Accepted: 2 June 2012 - Published: 18 June 2012

\begin{abstract}
Thermal structure associated with deep convective clouds is investigated using Global Positioning System (GPS) radio occultation measurements. GPS data are insensitive to the presence of clouds, and provide high vertical resolution and high accuracy measurements to identify associated temperature behavior. Deep convective systems are identified using International Satellite Cloud Climatology Project (ISCCP) satellite data, and cloud tops are accurately measured using Cloud-Aerosol Lidar with Orthogonal Polarization (CALIPSO) lidar observations; we focus on 53 cases of near-coincident GPS occultations with CALIPSO profiles over deep convection. Results show a sharp spike in GPS bending angle highly correlated to the top of the clouds, corresponding to anomalously cold temperatures within the clouds. Above the clouds the temperatures return to background conditions, and there is a strong inversion at cloud top. For cloud tops below $14 \mathrm{~km}$, the temperature lapse rate within the cloud often approaches a moist adiabat, consistent with rapid undiluted ascent within the convective systems.
\end{abstract}

\section{Introduction}

Deep convective systems play a fundamental role in atmospheric circulation and climate. Thunderstorms and mesoscale convective systems produce fast vertical transport, redistributing water vapor and chemical constituents and influencing the thermal structure of the Upper Troposphere and Lower Stratosphere (UTLS). Measurements of atmospheric parameters such as temperature and water vapor with high vertical resolution and accuracy near tropopause altitudes is difficult during severe weather events, and the processes that determine the details of UTLS transport are the subject of ongoing research (e.g., Pan et al., 2010). Hydration and dehydration of the UTLS are also poorly understood; models and measurements suggest that overshooting convection can penetrate the tropopause and, with different mechanisms, either hydrate or dehydrate the UT or the LS (Kley et al., 1982; Danielsen, 1993; Wang, 2003; Jensen et al., 2007; Corti et al., 2008).

The mean thermal structure in the tropics is linked to the influence of deep convection: a maximum in the observed lapse rate occurs near $12 \mathrm{~km}$, associated with the top of convective influence (Gettelman and Forster, 2002; Folkins and Martin, 2005). However, transient variability associated with deep convection is more difficult to identify, as balloon or aircraft measurements are difficult in regions of intense convection. Sherwood et al. (2003) used regular radiosonde measurements stratified according to the intensity of nearby convection to identify convective influence, identifying middle tropospheric warming and cooling at altitudes near the tropopause (typically above the top of convection). Such cooling can result from convective overshooting, and also from excitation of gravity or Kelvin waves by the convection (Garcia and Salby, 1987; Randel and $\mathrm{Wu}, 2005$ ). Chae et al. (2011) used 3-4 km thick layer measurements from the Aura Microwave Limb Sounder (MLS) to identify the average thermal structure of cloudy regions in the deep tropics, finding average cold temperatures $(\sim 2 \mathrm{~K})$ over $\sim 10-14 \mathrm{~km}$, and warm anomalies $(\sim 1 \mathrm{~K})$ above $(\sim 18 \mathrm{~km})$. In this paper 
we study the thermal structure of deep convective systems using observations from Global Positioning System (GPS) radio occultation measurements.

The GPS radio occultation (RO) technique (Kursinski et al., 1997) enables measurement of atmospheric thermal structure with high accuracy and vertical resolution in any meteorological condition, since the radiowave signal is not affected by clouds. Radio occultation soundings have the highest accuracy between 5 and $25 \mathrm{~km}$ of altitude with observational errors in the range $0.3-0.5 \%$ in refractivity (Kuo et al., 2004), and they have vertical resolution ranging from $60 \mathrm{~m}$ in the low troposphere to $1.5 \mathrm{~km}$ in the stratosphere and horizontal resolution of about $270 \mathrm{~km}$ (Kursinski et al., 2000). Several GPS RO missions are working at present, providing a high density of vertical profiles with a good time and space coverage (Biondi et al., 2011). Here we use GPS data to quantify the thermal structure of intense deep convection, based on identifying numerous GPS occultations that are co-located with large convective systems. The convective systems are identified using the International Satellite Cloud Climatology Project (ISCCP) Deep Convection Tracking Database (Rossow et al., 1996), and the detailed cloud structure (cloud top) is provided by Cloud-Aerosol Lidar and Infrared Pathfinder Satellite Observation (CALIPSO) measurements (Hunt et al., 2009).

\section{Data description}

\subsection{GPS data}

GPS observations are used from the Constellation Observing System for Meteorology, Ionosphere and Climate (COSMIC) six-satellite constellation (Anthes et al., 2008), the Gravity Recovery And Climate Experiment (GRACE) twin satellites (Beyerle et al., 2005), and the CHAllenging Minisatellite Payload (CHAMP) satellite (Wickert, 2001). The GPS RO data are obtained from the COSMIC Data Analysis and Archive Center (CDAAC) website (http://cosmic-io.cosmic. ucar.edu/cdaac/index.html). We focus here on the CHAMP, GRACE and COSMIC profiles covering the period 20062009, overlapping the CALIPSO measurement period.

The radio occultation technique uses the phase and amplitude of two L-band signals (L1 at $1575.42 \mathrm{MHz}$ and L2 at 1227.60 MHz) transmitted from GPS satellites and received by the GPS receivers on board of Low Earth Orbit (LEO) satellites (e.g. COSMIC). When the signal passes through the atmosphere it is refracted due to refractive index gradients and a measurement can be characterized by the bending angle, $\alpha$, as a function of the impact parameter $a$. Assuming local spherical symmetry, the refractive index, $n$ related to a given impact parameter $\left(a_{r_{p}}\right)$, can be derived from $\alpha$ and $a$ using the Abel inversion (Fjeldbo et al., 1971): $n\left(r_{p}\right)=\exp \left(\frac{1}{\pi} \int_{a_{r_{p}}}^{\infty} \frac{\alpha(a)}{\sqrt{a^{2}-a_{r_{p}}^{2}}} \mathrm{~d} a\right)$

The tangent radius, $r_{p}$, is subsequently found from the relation $a_{r_{p}}=n\left(r_{p}\right) r_{p}$. The refractivity profile is then:

$N=(n-1) \times 10^{6}$

Atmospheric refractivity $(N)$ is dependent on the temperature ( $T$ in Kelvin), pressure ( $p$ in millibar) and water vapor pressure ( $e$ in millibar) profiles according to:

$N=77.6 \times \frac{p}{T}+3.73 \times 10^{5} \times \frac{e}{T^{2}}$

The water vapor term (proportional to $\frac{e}{T^{2}}$ ) is small in the upper troposphere and stratosphere, where the water vapor mixing ratios are $<100 \mathrm{ppmv}$, so that the refractivity can be used to directly calculate the so-called dry temperature and dry pressure. More generally Eq. (3) can be solved to obtain estimates of $e, p$, and $T$ by assimilating the refractivity together with first-guess profiles from, e.g., ECMWF analyses, using a one-dimensional variational (1DVar) technique (e.g., Healy and Eyre, 2000). The temperature profiles presented in this paper were derived at CDAAC using a 1Dvar approach, but where refractivity observations are heavily weighted such that the resulting temperature is basically the same as the dry temperature in regions where the water wapor term is insignificant (Biondi et al., 2011). We have analyzed the following GPS level 2 data products available from CDAAC:

1. Atmospheric Profile (atmPrf), which is a product containing the bending angle, refractivity, impact parameter and the so-called dry pressure and dry temperature (derived assuming no water vapor). All the parameters are reported versus the geometric height above the mean sea level and the coordinates of the perigee point.

2. European Centre for Medium-Range Weather Forecasts (ECMWF) Profiles (ecmPrf), which is a low resolution product generated from the ECMWF gridded analysis (ECMWF TOGA 2.5 degree Global Surface and Upper Air Analysis) for 00:00:00 UTC and 12:00:00 UTC each day, co-located with occultation profiles for comparison purposes. It contains refractivity, pressure, temperature and moisture profile versus 21 standard pressure levels $(1000,925,850,700,500,400,300,250$, $200,150,100,70,50,30,20,10,7,5,3,2$ and $1 \mathrm{hPa})$ and coordinates. Although a higher resolution would have been preferable, these low-resolution analyses are used for comparison to the higher resolution GPS measurements because the co-located profiles are readily available from the CDAAC archive. 
3. Wet Profile (wetPrf), which is an interpolated product with a vertical resolution of $100 \mathrm{~m}$ obtained using a one dimensional variational (1DVar) technique together with ECMWF low resolution analysis data. This profile contains latitude and longitude of the perigee point, pressure, temperature, water vapor pressure, refractivity and mean sea level altitude of the perigee point.

\subsection{Cloud measurements}

Detailed information on the space-time behavior of convective systems comes from the ISCCP Deep Convection Tracking Database, which is a globally gridded product with a nominal time resolution of $3 \mathrm{~h}$ and horizontal resolution of $30 \mathrm{~km}$. This is a database created to identify and describe the properties of mesoscale deep convective cloud systems (Rossow et al., 1996), using brightness temperatures from geostationary satellite measurements. Convective Systems (CS) are detected by cloud top temperatures $<245 \mathrm{~K}$, and Convective Clusters (CC) are identified as adjacent cloudy pixels with cloud top temperatures $<220 \mathrm{~K}$. The CS represents all high-level cloud systems, including isolated cirrus, deep convective towers, and anvil clouds. The dataset provides information related to location, size, shape and the properties of the clouds, including CC in case they are present, their location and properties.

The detailed vertical structure of clouds (and in particular the cloud top altitude) is studied using the Cloud-Aerosol Lidar with Orthogonal Polarization (CALIOP) instrument on board the CALIPSO satellite. The CALIPSO lidar measurements provide high-resolution vertical profiles of aerosols and clouds along satellite orbit tracks (equator crossing time 01:30:00 and 13:30:00 local solar time), with horizontal resolution of $333 \mathrm{~m}$ and vertical resolution between 30 and $60 \mathrm{~m}$ depending on the altitude working at two-wavelength $(532 \mathrm{~nm}, 1064 \mathrm{~nm})$. The CALIPSO data are available from June 2006 and we used the lidar product level 1 (CAL LID_L1), release ValStage1 and version V03 to analyze the total attenuated backscatter.

\section{Methods}

\subsection{GPS measurements and background climatology}

Using all the GPS ROs collected from the CDAAC website from 1995 to 2009, we have created a gridded monthly climatology (with one-degree latitude-longitude resolution) containing the averaged bending angle and temperature profiles. This climatology is used to compare with the profiles nearby to deep convection to identify anomalous bending angle and temperature behavior.

One key parameter that we analyze and discuss in this paper is the bending angle percentage anomaly with respect to the climatology (Biondi et al., 2011):

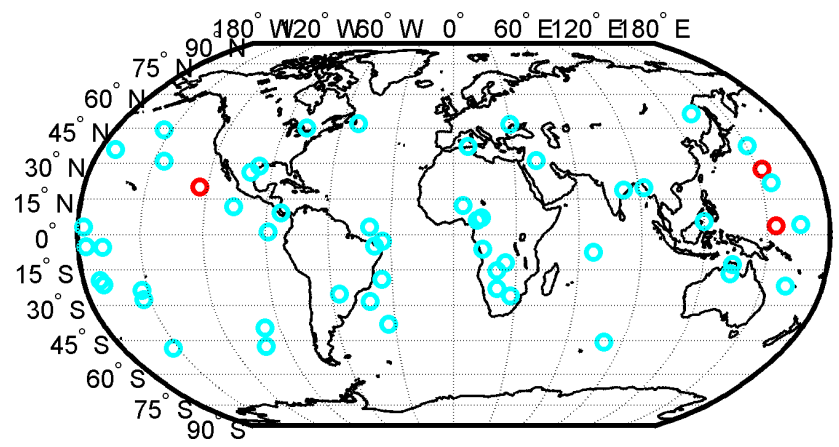

Fig. 1. Locations of the Convective Clusters co-located with GPS radio occultations described in Table 1 . In red the cases detailed in paragraph 4.

$\alpha_{\%}=100 \cdot\left(\frac{\alpha_{\text {conv }}-\alpha_{\text {clim }}}{\alpha_{\text {clim }}}\right)$

where $\alpha_{\text {conv }}$ is the bending angle profile for the convective systems and $\alpha_{\text {clim }}$ is the climatological bending angle from the gridded reference. All of the analyses are based on the raw (unoptimized) bending angle from the atmPrf product and the temperature profiles form the wetPrf product.

\subsection{Identifying co-locating GPS, ISCCP and CALIPSO measurements}

Our objective is to identify GPS occultations which are colocated with large-scale intense deep convective systems (from ISCCP data), and furthermore closely overlap with the CALIPSO orbital track data. We focus on the period June 2006-July 2008 (which is the period of availability of ISCCP Deep Convection Tracking Database and CALIPSO), and selected 2157 cases of coincidences of Convective Clusters (CC) with GPS occultations, where the GPS measurements occur in a time window of $2 \mathrm{~h}$ and within the actual radius of the CC. Since we are interested in the study of the UTLS, we compared the storm location with the RO tangent point coordinates at $15 \mathrm{~km}$ of altitude.

We then further identify cases where CALIPSO observations occur within the spatial radius of the $\mathrm{CC}$, and within a time window of $2 \mathrm{~h}$. This results in 53 cases where the GPS RO is co-located with CALIPSO (Fig. 1), within a Convective Cluster (Table 1); these 53 events form the basis for our analysis below. These convective systems span a wide range of latitudes $\left(\sim 50^{\circ} \mathrm{N}-\mathrm{S}\right)$ and longitudes; 20 cases are within the latitude band $15^{\circ} \mathrm{N}-\mathrm{S}$, and 38 within $30^{\circ} \mathrm{N}-\mathrm{S}$. The cloud top altitude from CALIOP is defined as the maximum height where the total attenuated backscatter at $532 \mathrm{~nm}$ is larger than the background noise. 


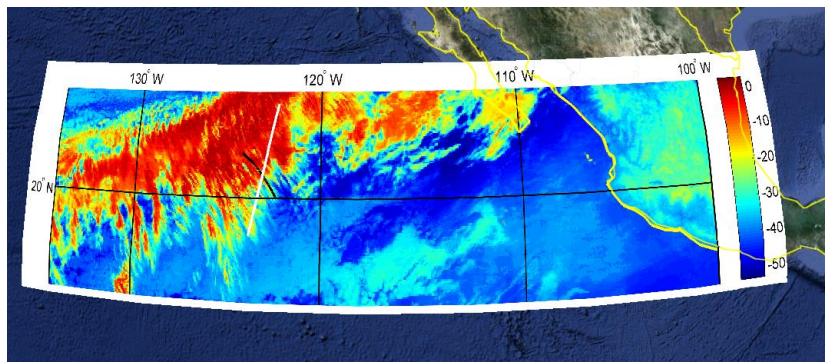

Fig. 2. Structure of a convective system in the eastern Pacific ocean (2 February 2008). Colors denote GOES brightness temperature (09:45:00 UTC) difference between the 6.5 micron and 11 micron channels, with red denoting high, cold clouds. The black line is the GPS RO tangent point (09:53:00 UTC) and the white line is the CALIPSO track (10:08:00 UTC).

\section{Results}

We first highlight results from an individual case study, with the spatial structure illustrated in Fig. 2. In this case the Convective System was located on the eastern Pacific basin on 2 February 2008 , covering a broad region between $\sim 120^{\circ} \mathrm{W}$ and $130^{\circ} \mathrm{W}$, polewards of $20^{\circ} \mathrm{N}$. The convective system radius was $208 \mathrm{~km}$ and the convective cluster radius was $30 \mathrm{~km}$. Figure 2 shows the GOES brightness temperature difference between the 6.5 micron and 11 micron channels (which highlights high altitude clouds) at 09:45:00 UTC, together with the GPS RO tangent point (bold black line, centered near $21^{\circ} \mathrm{N} ; 123^{\circ} \mathrm{W}$ ) and the CALIPSO track (bold white line). The GPS RO was acquired at 09:53:00 UTC in a Convective Cluster with minimum temperature of $210 \mathrm{~K}$. CALIPSO overpassed the storm just $15 \mathrm{~min}$ later, at 10:08:00 UTC, $32 \mathrm{~km}$ from the RO tangent point.

Figure 3 (left panel) shows the total attenuated backscatter from CALIOP along the orbit track in Fig. 2 as a function of altitude, highlighting a relatively flat cloud top near $12.5 \mathrm{~km}$. The right panels in Fig. 3 show the corresponding bending angle anomaly from GPS RO (green line), together with the temperature profile from GPS RO (red line), the temperature profile from the ECMWF analysis (cyan) at 12:00:00 UTC, and the climatological temperature profile (blue line). The bending angle anomaly profile has a large positive spike centered near $12.5 \mathrm{~km}$, very close to the altitude of the cloud top identified by CALIPSO. The GPS temperature profile shows that the upper cloud layer corresponds to relative cold anomalies (compared to the background climatology), with a relative cold point near the cloud top (coincident with the maximum bending angle anomaly). In this case the maximum cold anomaly is approximately $9 \mathrm{~K} \mathrm{com-}$ pared to the background climatology. The CALIOP attenuated backscatter shows the maximum cloud top at $12.64 \mathrm{~km}$ and the altitude of the top (averaged over the satellite track) at $12.16 \mathrm{~km}$. Below the cloud (not shown), the temperature follows the climatological profiles up to approximately $9 \mathrm{~km}$; above $9 \mathrm{~km}$ the lapse rate within the cloud increases, reaching about $10 \mathrm{~K} \mathrm{~km}^{-1}$ just below the cloud top. There is a strong inversion near the cloud top, and above the cloud the temperature becomes warmer than the climatology, although this latter behavior is not observed in every case (or in the average statistics shown below). The temperature profile from the ECMWF analysis agrees with the profile from GPS RO, but smears out the detailed vertical structure near the cloud top due to the coarse vertical resolution; in particular the sharp warming above the cloud is not well resolved.

Two further examples of temperature profiles acquired during intense convective systems with cloud tops reaching different altitudes are shown in Fig. 4. The first case (Fig. 4a) was in January 2008 in Micronesia (with CS radius of $428 \mathrm{~km}$ and $\mathrm{CC}$ radius of $104 \mathrm{~km}$ ), where the cloud top altitude reached an altitude $(16.8 \mathrm{~km})$ near the tropical tropopause. This is associated with a sharp maximum in bending angle anomaly, and cold temperatures (up to $8 \mathrm{~K}$ ) compared to the background climatology. The second case (Fig. 4b) was in April 2008 in the western Pacific basin (CS radius $196 \mathrm{~km}$ and CC radius $77 \mathrm{~km}$ ), with a cloud top altitude near $14 \mathrm{~km}$. In this case the bending angle anomaly was more than $30 \%$, with a temperature anomaly near the cloud top of $\sim 12 \mathrm{~K}$, and a strong inversion above. The ECMWF analysis produces a low resolution version of this detailed structure completely missing the strong inversion, the temporal mismatch between the analysis and the RO could be a reason for the differences.

The previous 3 cases were chosen because representing 3 different areas of the globe and their cloud top reached different altitudes ranging from 12 to $17 \mathrm{~km}$. In all the cases analyzed here, the bending angle anomaly shows a spike in the UTLS (corresponding to a relative cold point in the temperature profile) with altitude lower than the standard tropopause, frequently revealing a double tropopause structure. This may be one mechanism for the (infrequent) occurrence of double tropopauses in the tropics observed in GPS data (Schmidt et al., 2006; Randel et al., 2007).

Figure 5 shows a scatter plot of the altitude of the bending angle anomaly spike versus the maximum cloud top altitude from CALIOP, for each of the 53 cases considered here. This shows remarkably good agreement, with a correlation of 0.93 and a root mean square difference of $0.85 \mathrm{~km}$. Since the GPS $\mathrm{RO}$ and CALIPSO track are never exactly co-located we also compare the bending angle profile with the altitude of the cloud averaged over the satellite track (Fig. 6), and this results in a slightly lower correlation (0.85) and an apparent bias (wherein the averaged CALIPSO cloud top is $\sim 1 \mathrm{~km}$ lower than the bending angle anomaly).

Using the cloud top altitude from CALIOP as a reference, we plotted the bending angle anomalies (Fig. 7), temperature anomaly profiles (Fig. 8), and lapse rate ( $-\mathrm{d} T / \mathrm{d} z$ ) (Fig. 9), as a function of altitude below and above the cloud top. These statistics are separated into cases where the cloud top altitude is below ( 22 cases) or above $14 \mathrm{~km}$ ( 31 cases), in order to identify any systematic differences with the depth of 
Table 1. Convective Clusters co-located with GPS radio occultation and CALIPSO track. The local time is related to the RO acquisitions. The space distance is related to GPS radio occultation tangent point at $15 \mathrm{~km}$ of altitude and the closest CALIPSO track coordinates. In bold the cases detailed in the paragraph 4 and in italic the cases on land.

\begin{tabular}{|c|c|c|c|c|c|}
\hline Date & Local Time & Distance $[\mathrm{km}]$ & $\mathrm{CS} \operatorname{rad}[\mathrm{km}]$ & $\mathrm{CC} \operatorname{rad}[\mathrm{km}]$ & Area \\
\hline $26 / 11 / 2006$ & 02.33 p.m. & 45 & 160 & 16 & China \\
\hline $20 / 01 / 2007$ & 03:19 a.m. & 85 & 102 & 53 & Kiribati \\
\hline $26 / 01 / 2007$ & 02:22 p.m. & 84 & 131 & 69 & Polynesia \\
\hline $28 / 01 / 2007$ & 12.43 p.m. & 72 & 92 & 67 & Paraguay \\
\hline $30 / 01 / 2007$ & 02:19 a.m. & 95 & 292 & 155 & North Pacific \\
\hline $01 / 02 / 2007$ & 02:18 a.m. & 49 & 394 & 134 & Australia \\
\hline 03/02/2007 & 00:48 a.m. & 69 & 203 & 102 & South-West Pacific \\
\hline 04/02/2007 & 12:40 p.m. & 57 & 118 & 16 & Polynesia \\
\hline 04/02/2007 & 01:03 a.m. & 87 & 396 & 53 & Central Atlantic \\
\hline $13 / 02 / 2007$ & 00:58 a.m. & 92 & 132 & 47 & Brazil \\
\hline $10 / 03 / 2007$ & 03:31 a.m. & 90 & 109 & 50 & USA - Texas \\
\hline $17 / 03 / 2007$ & $02: 21$ p.m. & 79 & 102 & 97 & Guyana \\
\hline 28/03/2007 & 02:23 p.m. & 54 & 92 & 61 & Botswana \\
\hline $11 / 04 / 2007$ & 03:23 p.m. & 93 & 146 & 117 & South Atlantic \\
\hline $18 / 04 / 2007$ & 01:31 p.m. & 94 & 191 & 65 & Galapagos \\
\hline $30 / 05 / 2007$ & 03:04 a.m. & 50 & 256 & 61 & South Atlantic \\
\hline 02/06/2007 & 01:58 a.m. & 58 & 919 & 225 & South Atlantic \\
\hline $02 / 06 / 2007$ & 02:45 p.m. & 59 & 214 & 82 & Ukraine \\
\hline 02/06/2007 & 02:08 a.m. & 78 & 161 & 29 & South-West Pacific \\
\hline 05/06/2007 & 12:35 p.m. & 65 & 236 & 134 & India \\
\hline 08/06/2007 & 01:51 a.m. & 76 & 296 & 87 & South Pacific \\
\hline 02/07/2007 & 02:40 p.m. & 84 & 251 & 73 & Indian Ocean \\
\hline 03/07/2007 & 02:31 a.m. & 85 & 183 & 29 & South Pacific \\
\hline 03/07/2007 & 02:07 p.m. & 94 & 110 & 44 & USA - Texas \\
\hline 20/07/2007 & 02:08 a.m. & 82 & 533 & 82 & Bay of Bengal \\
\hline 02/08/2007 & 02:29 a.m. & 93 & 246 & 63 & Philippines \\
\hline 07/08/2007 & 12:25 p.m. & 68 & 100 & 29 & China \\
\hline $14 / 08 / 2007$ & 03:09 a.m. & 57 & 104 & 58 & Nigeria \\
\hline $27 / 09 / 2007$ & 01:38 p.m. & 95 & 117 & 95 & Sierra Leone \\
\hline 09/10/2007 & 02:10 a.m. & 72 & 137 & 110 & East Pacific \\
\hline $02 / 12 / 2007$ & 02:50 a.m. & 98 & 156 & 108 & Australia \\
\hline $04 / 12 / 2007$ & 03:09 p.m. & 55 & 109 & 44 & South Africa \\
\hline $06 / 12 / 2007$ & 01:14 p.m. & 80 & 226 & 16 & Central Pacific \\
\hline $13 / 12 / 2007$ & 02:00 a.m. & 99 & 425 & 182 & Japan \\
\hline 09/01/2008 & 02:18 a.m. & 47 & 135 & 67 & Canada \\
\hline $10 / 01 / 2008$ & 01:53 p.m. & 70 & 353 & 75 & Angola \\
\hline $15 / 01 / 2008$ & 01:29 p.m. & 57 & 175 & 108 & North Atlantic \\
\hline $22 / 01 / 2008$ & 00:58 a.m. & 18 & 428 & 104 & Micronesia \\
\hline $02 / 02 / 2008$ & 01:53 a.m. & 32 & 208 & 30 & East Pacific \\
\hline $15 / 02 / 2008$ & 11:41 p.m. & 58 & 238 & 29 & Micronesia \\
\hline $02 / 03 / 2008$ & 03:07 p.m. & 76 & 137 & 56 & Zaire \\
\hline 19/03/2008 & 02:01 p.m. & 93 & 92 & 79 & Cameroon \\
\hline 29/03/2008 & 03:10 a.m. & 92 & 94 & 56 & Samoa \\
\hline 03/04/2008 & 03:25 p.m. & 71 & 122 & 95 & Sulu Sea \\
\hline $12 / 04 / 2008$ & 01:39 p.m. & 72 & 315 & 116 & Iraq \\
\hline $12 / 04 / 2008$ & 01:36 a.m. & 42 & 395 & 87 & Cook Island \\
\hline $14 / 04 / 2008$ & 03:07 a.m. & 64 & 196 & 77 & West Pacific \\
\hline 01/05/2008 & 01:45 a.m. & 69 & 146 & 53 & South Pacific \\
\hline 07/05/2008 & 02:30 a.m. & 77 & 171 & 86 & North Pacific \\
\hline $30 / 05 / 2008$ & 01:33 a.m. & 95 & 109 & 33 & New Caledonia \\
\hline 02/06/2008 & 01:53 a.m. & 39 & 112 & 44 & Atlantic \\
\hline $21 / 06 / 2008$ & 01:23 a.m. & 38 & 211 & 77 & South Atlantic \\
\hline 28/06/2008 & 03:01 a.m. & 99 & 92 & 81 & Costa Rica \\
\hline
\end{tabular}



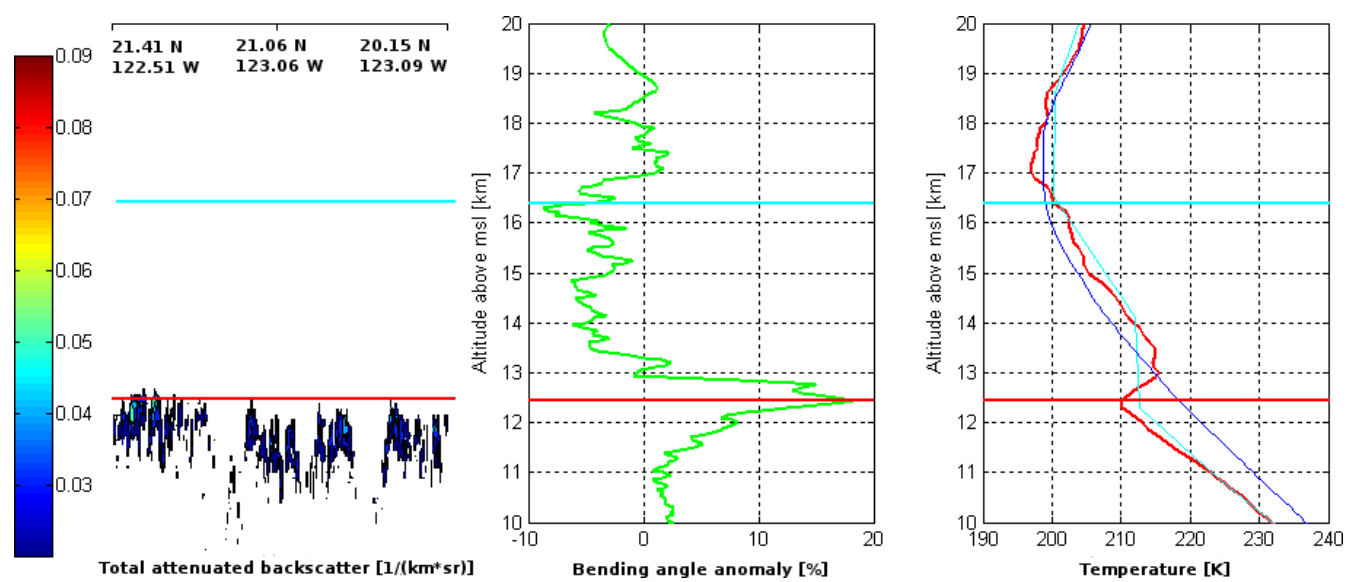

Fig. 3. Vertical profile associated with the convective system identified in Fig. 2 (2 February 2008). The left panel shows the total attenuated backscatter at $532 \mathrm{~nm}$ from CALIOP (10:08:00 UTC), along the orbit track shown in Fig. 2. The right panels show the bending angle anomaly profile (green) and the temperature profile (red) from GPS RO (09:53:00 UTC) during the storm. The temperature plot also shows the profile from the ECMWF analysis (cyan) and the climatological temperature profile (blue). The horizontal cyan line is the altitude of the standard tropopause and the horizontal red line is the altitude of the coldest point and the bending angle anomaly spike.
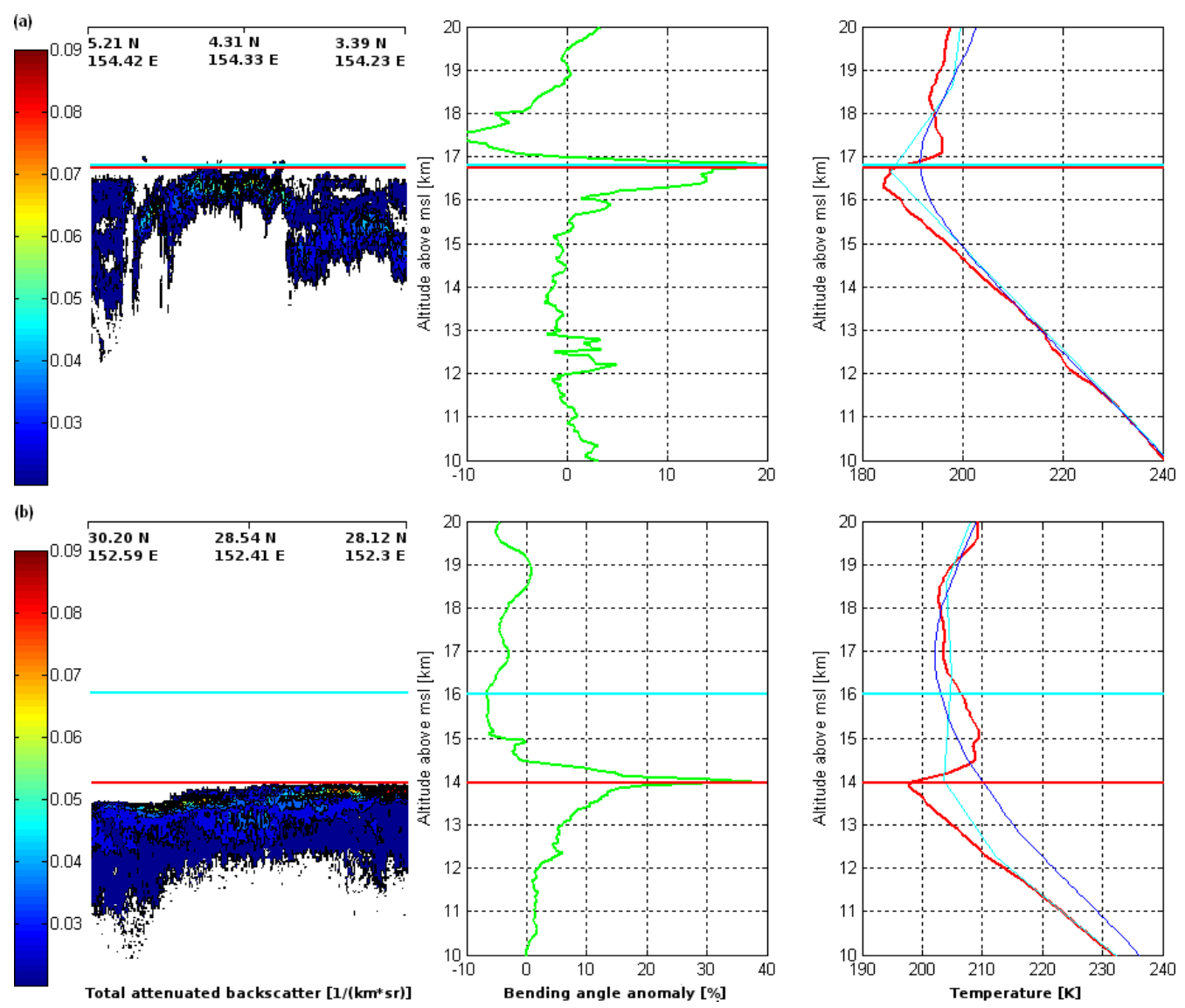

Fig. 4. Two examples of convective systems reaching different altitude: 22 January 2008 at 14:58:00 UTC (top panel) and 14 April 2008 at 17:07:00 UTC (bottom panel). The left panels show the total attenuated backscatter at $532 \mathrm{~nm}$ from CALIOP (at 15:28:00 UTC and 15:54:00 UTC, respectively), and the right panels show the bending angle anomaly profile (green), the temperature profile from GPS RO during the storm (red), the temperature profile from ECMWF analysis (cyan) and the climatological temperature profile (blue). The horizontal cyan line is the altitude of the standard tropopause and the horizontal red line is the altitude of the coldest point and the bending angle anomaly spike. 


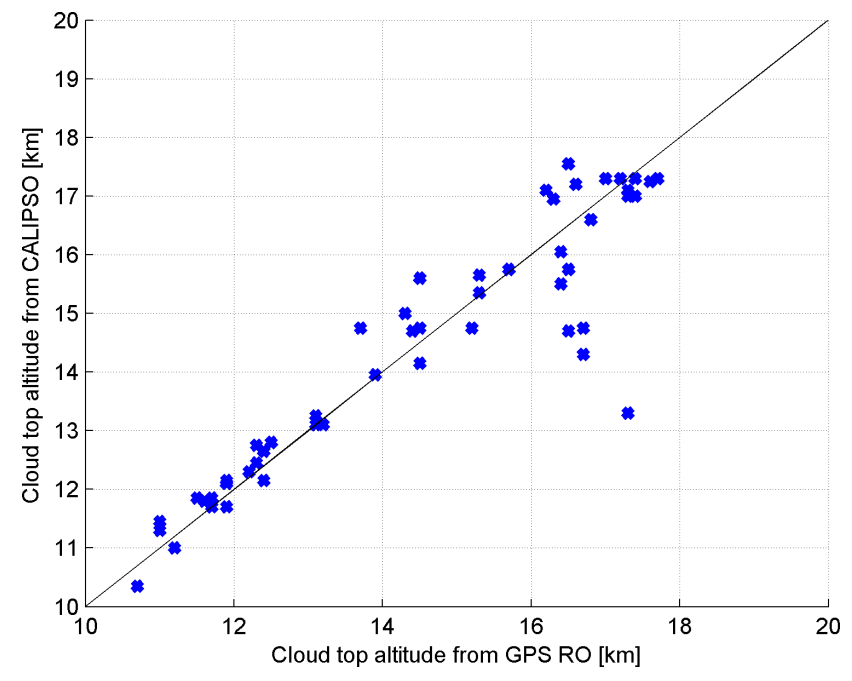

Fig. 5. Scatter plot showing correlation between cloud top height derived from GPS RO (identified from the maximum bending angle anomaly) and the maximum cloud top height from CALIOP.

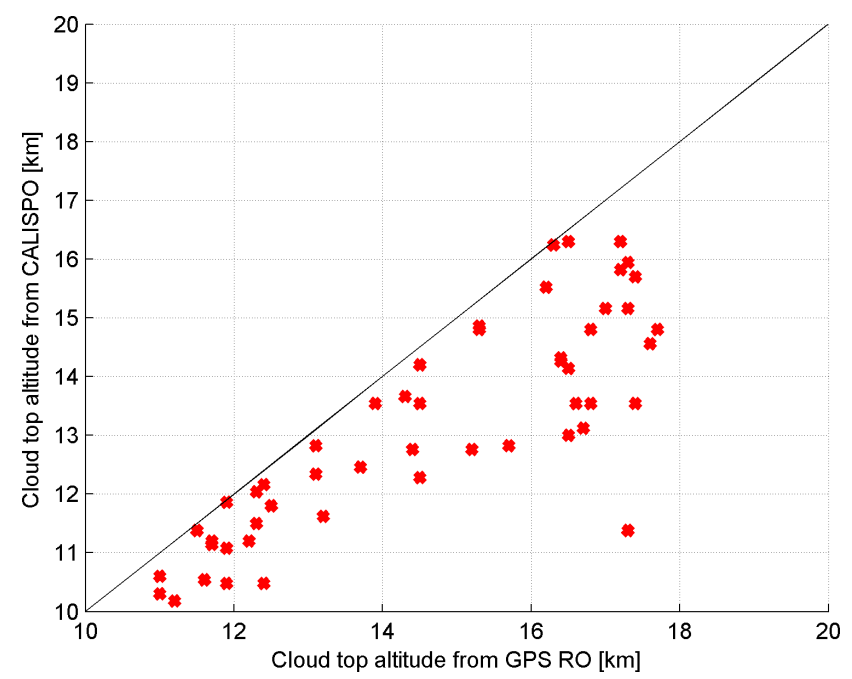

Fig. 6. Scatter plot between cloud top height from GPS ROs (as in Fig. 4) and the average cloud top height (averaged along the satellite orbit track) from CALIOP.

convection. The bending angle anomalies (Fig. 7) show a strong maximum near cloud top. The average bending angle percentage anomaly is $10 \%$ (reaching above $30 \%$ for the event shown in Fig. 4b). The overall anomaly signals are stronger for profiles where the cloud tops are below $14 \mathrm{~km}$ (Fig. 7b). Temperature anomalies (Fig. 8) show relative coldest differences near the cloud top (consistent with the largest bending angle anomalies). The mean temperature anomaly is somewhat larger $(\sim 8 \mathrm{~K})$ for cloud tops below $14 \mathrm{~km}$, compared to cloud tops above $14 \mathrm{~km}(\sim 3 \mathrm{~K})$. For cloud tops below $14 \mathrm{~km}$, the temperature anomalies decrease with altitude above the cloud; for higher cloud tops, the anomalies rapidly
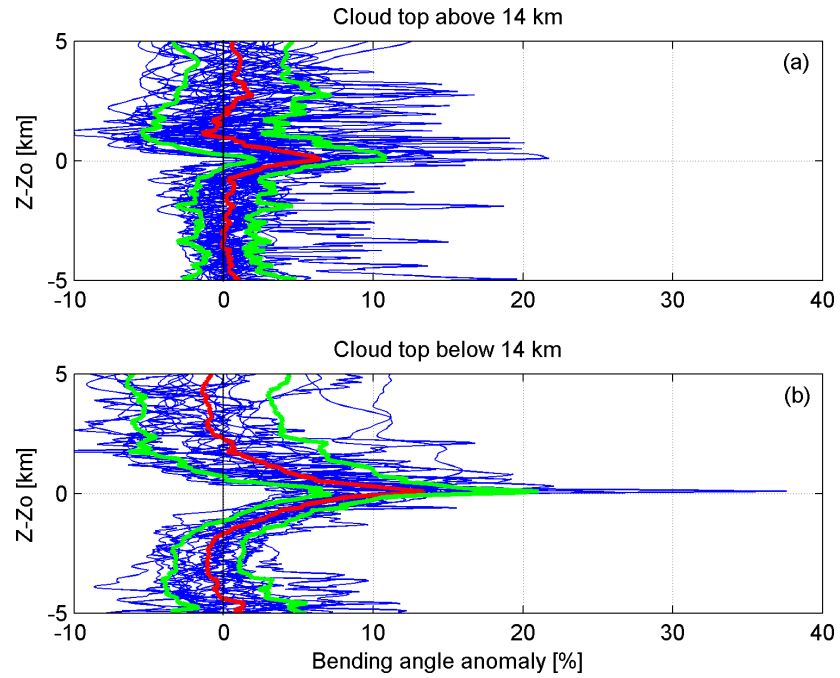

Fig. 7. Vertical profile of the GPS bending angle anomaly, calculated with respect to the altitude of the cloud top derived from the corresponding CALIOP measurements. Blue lines show each of the 53 cases, separated according to cloud top above and below $14 \mathrm{~km}$. The red line is the average and the green lines are the average \pm one standard deviation.
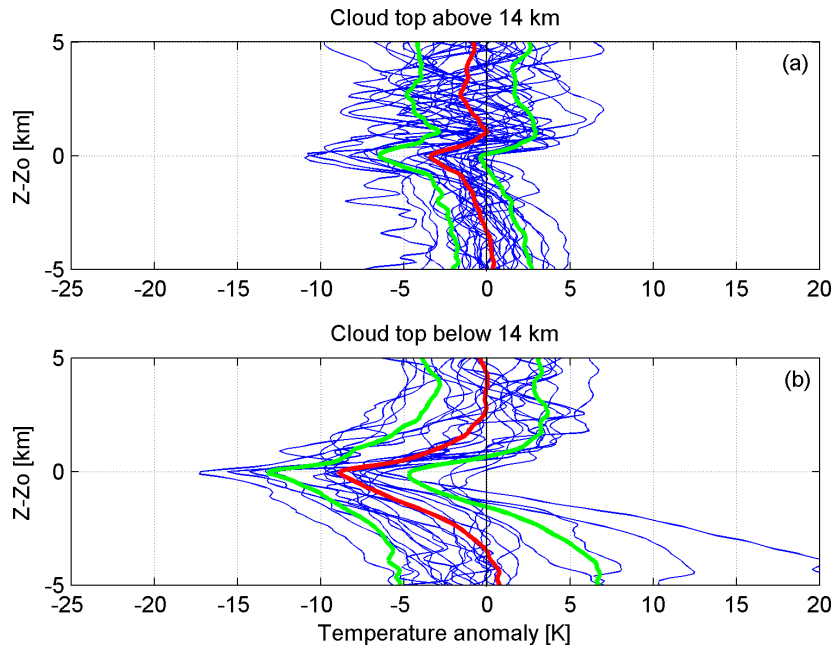

Fig. 8. Vertical profile of the GPS temperature difference between the convective system and the background climatology, calculated with respect to the altitude of the cloud top derived from the corresponding CALIOP measurements. Blue lines show each of the 53 cases, separated according to cloud top above and below $14 \mathrm{~km}$. The red line is the average and the green lines are the average \pm one standard deviation.

die off beyond $z-z 0=5 \mathrm{~km}$. We decided to use $14 \mathrm{~km}$ of altitude as discriminator because the correlation between samples below $14 \mathrm{~km}$ is higher than the correlation between samples above $14 \mathrm{~km}$.

Figure 9 compares the lapse rate $(-\mathrm{d} T / \mathrm{d} z)$ structure associated with the convective systems, and for comparison the 

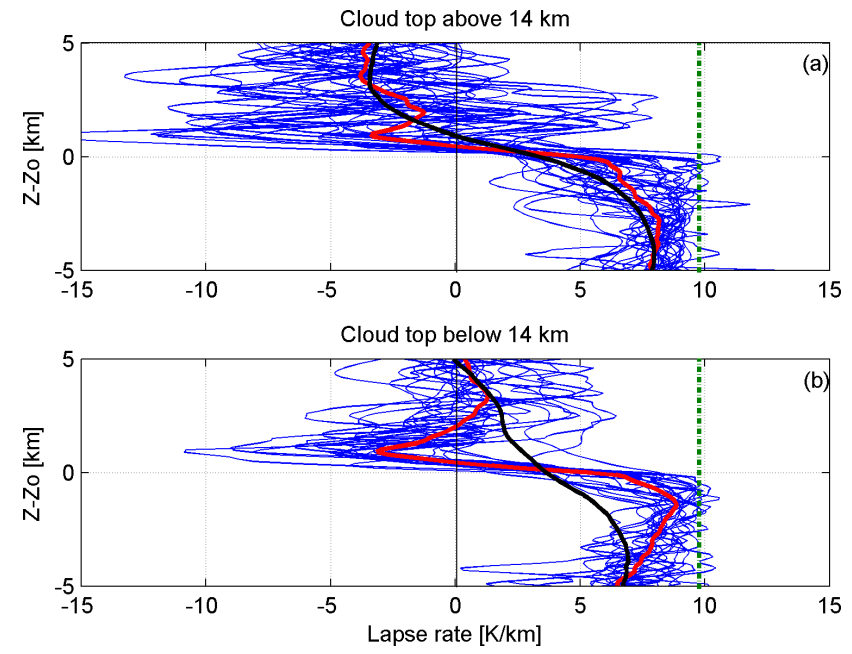

Fig. 9. Vertical profile of the GPS lapse rate $(-\mathrm{d} T / \mathrm{d} z)$ calculated with respect to the altitude of the cloud top derived from the corresponding CALIOP measurements for 53 convective systems (blue lines). The red line is the convective systems average, the black line is the averaged climatological lapse rate and the dotted vertical green line is the dry adiabatic lapse rate $\left(9.8 \mathrm{~K} \mathrm{~km}^{-1}\right)$.

climatological background lapse rate is also included (black line). The colder temperatures within the clouds result in a significantly larger lapse rate below cloud top, especially for the cases with cloud tops below $14 \mathrm{~km}$ (Fig. 9b). In these cases the observed convective system lapse rates often approach a wet adiabat, consistent with rapid undiluted ascent within the convective system. The wet adiabat lapse rate (e.g. $9 \mathrm{~K} \mathrm{~km}^{-1}$ at $300 \mathrm{hPa}$ and $-40^{\circ} \mathrm{C}$ ) is less than the dry adiabatic lapse rate of $9.8 \mathrm{~K} \mathrm{~km}^{-1}$. Above the cloud top the lapse rate typically becomes negative, corresponding to the systematic inversion seen in the temperature profiles above cloud top (e.g. Figs. 3-4).

\section{Conclusions}

This study has utilized GPS RO temperature profiles to investigate the thermal structure associated with deep convective systems, as identified in co-located ISCCP and CALIPSO data. The GPS data are well suited to this problem, as the radiowave signals are unaffected by clouds. The results show systematic anomalies in RO bending angle closely aligned with the top of convective systems (Fig. 5); it is important to appreciate that these results are derived from completely independent data sets (namely satellite radio occultation vs. space-based lidar measurements). These bending angle anomalies are associated with cold temperature anomalies over the cloud layer, peaking near cloud top. A schematic of the thermal structure of the convective systems derived from the results here is shown in Fig. 10. Temperatures decrease from the surface with a standard lapse rate until

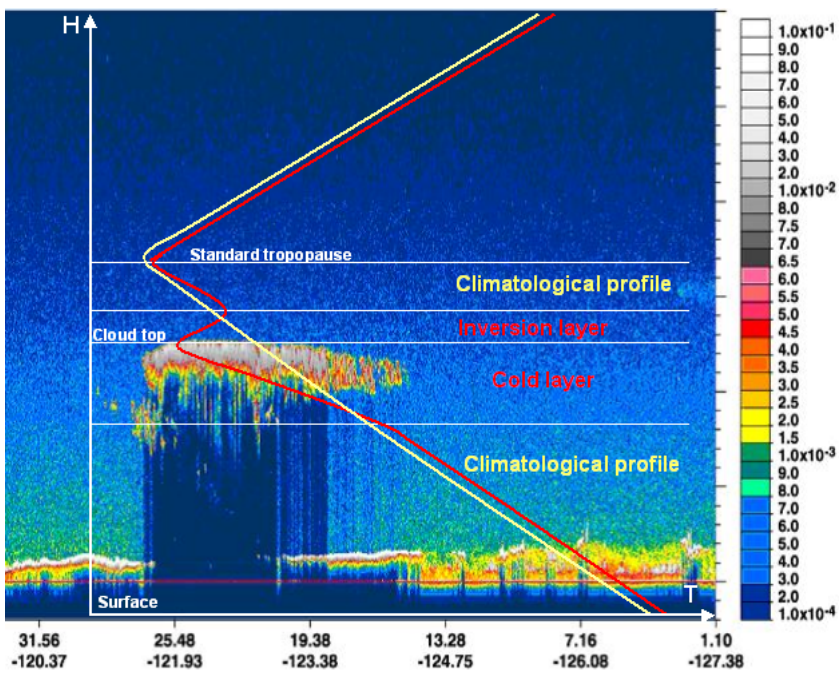

Fig. 10. Atmospheric thermal structure associated with intense convective systems, as observed by GPS RO. The yellow line shows a background climatological temperature profile and the red line is the temperature profile when a convective system is present. The background figure is the CALIOP total attenuated backscatter for the case 2 February 2008.

a few kilometers from the cloud top. At this altitude the lapse rate increases (often approaching a moist adiabatic lapse rate, as quantified in Fig. 9) and revealing a relative temperature minimum (cold point) near the top of the convective system. Above the cloud top a strong inversion occurs, re-establishing a climatological temperature profile at higher altitudes. These upper level inversions are qualitatively similar to the lower level boundary layer inversions observed by GPS measurements in Sokolovskiy et al. (2007). For cloud-top altitudes well below the tropical tropopause $(\sim 17 \mathrm{~km})$, the cloud-top inversion layers often result in a double tropopause structure, with the lower one at the altitude of the cloud top and the higher one at the climatological tropopause. As a note, there is reasonable agreement between the GPS RO temperature profiles and nearby ECMWF analysis (Figs. 3-4), although much of the high resolution vertical structure revealed in GPS measurements is missed in the ECMWF profiles.

There are several aspects of the results presented here which argue that the GPS bending angle and temperature results are robust aspects of intense convective systems. As noted above, completely independent measurements (lidar vs. GPS RO) identify cloud top altitudes with an agreement of less than $1 \mathrm{~km}$ (Fig. 5). Further, very similar thermal structure is observed in many of the individual cases, especially for the 21 cases with cloud tops below $14 \mathrm{~km}$ (Figs. 7-9). In these cases, the lapse rate structure identifies a physically plausible behavior of approaching a moist adiabat at upper levels within the cloud system, consistent with rapid, unmixed ascent. As a note, the convective systems 
are also associated with enhanced water vapor over the altitudes of the cloud (up to several hundred ppmv according to collocated AIRS (Randel and Park, 2006) measurements). While these enhanced water vapor amounts will contribute to refractivity anomalies (Eq. 3), the corresponding changes in temperature are expected to be small $(<0.5 \mathrm{~K}$; S. Sokolovskiy, personal communication, 2011), and hence this is not an important source of bias in our results. The assumption of spherical symmetry inherent in the GPS refractive index retrieval may also be violated for the measurements near strong convective systems, although this probably does not introduce large biases.

It is interesting to compare the results of this study with the recent analysis of Chae et al. (2011), based on MLS temperatures combined with CALIOP cloud data. Note that there are significant differences between the temperature data used in these studies, namely the use of MLS temperatures with vertical resolution of $\sim 3-4 \mathrm{~km}$ (versus $<1 \mathrm{~km}$ for GPS RO), and much more extensive sampling for MLS (daily measurements spanning the tropics over 9 months vs. 53 individual cases studied here). The Chae et al. (2011) results reveal systematic cool temperatures below cloud top for cloudy regions, with average differences of $\sim 1-2 \mathrm{~K}$. This vertical structure is similar to the GPS results; the larger average temperature anomalies identified in our study may reflect a choice of isolating the most intense convective systems, or the higher vertical resolution of the GPS data. Chae et al. (2011) also identify systematic warm anomalies above cloud top, which are absent in our average results. The cause of this difference is difficult to identify given the very different temperature data sets and associated sampling behavior.

Acknowledgements. The authors thank Joan Alexander, Rick Anthes, Chris Davis, and Rich Rotunno for discussions and comments on the manuscript. Much of this work was accomplished while Riccardo Biondi was a visitor to the Atmospheric Chemistry Division at NCAR. The National Center for Atmospheric Research is sponsored by the US National Science Foundation.

Edited by: T. J. Dunkerton

\section{References}

Anthes, R. A., Bernhardt, P. A., Chen, Y., Cucurull, L., Dymond, K. F., Ector, D., Healy, S. B., Ho, S.-H., Hunt, D. C., Kuo, Y.-H., Liu, H., Manning, K., McCormick, C., Meehan, T. K., Randel, W. J., Rocken, C., Schreiner, W. S., Sokolovskiy, S. V., Syndergaard, S., Thompson, D. C., Trenberth, K. E., Wee, T.-K., Yen, N. L., and Zeng, Z.: The COSMIC/Formosat/3 mission: Early results, B. Am. Meteorol. Soc., 89, 313-333, 2008.

Beyerle, G., Schmidt, T., Michalak, G., Heise, S., Wickert, J., and Reigber, Ch.: GPS radio occultation with GRACE: Atmospheric Profiling utilizing the zero difference technique, Geophys. Res. Lett., 32, L13806, doi:10.1029/2005GL023109, 2005.
Biondi, R., Neubert, T., Syndergaard, S., and Nielsen, J. K.: Radio occultation bending angle anomalies during tropical cyclones, Atmos. Meas. Tech., 4, 1053-1060, doi:10.5194/amt-4-10532011, 2011.

Chae, J. H., Wu, D. L., Read, W. G., and Sherwood, S. C.: The role of tropical deep convective clouds on temperature, water vapor, and dehydration in the tropical tropopause layer (TTL), Atmos. Chem. Phys., 11, 3811-3821, doi:10.5194/acp-11-38112011, 2011.

Corti, T., Luo, B. P., deReus, M., Brunner, D., Cairo, F., Mahoney, M. J., Matucci, G., Matthey, R., Mitev, V., dos Santos, F. H., Schiller, C., Shur, G., Sitnikov, N. M., Spelten, N., Vössing, H. J., Borrmann, S., and Peter, T.: Unprecedented evidence for overshooting convection hydrating the tropical stratosphere, Geophys. Res. Lett., 35, L10810, doi:10.1029/2008GL033641, 2008.

Danielsen, E. F.: In situ evidence of rapid, vertical, irreversible transport of lower tropospheric air into the lower tropical stratosphere by convective cloud turrets and by larger-scale upwelling in tropical cyclones, J. Geophys. Res., 98, 8665-8681, 1993.

Fjeldbo, G., Kliore, A. J., and Eshleman, V. R.: The Neutral Atmosphere of Venus as Studied with the Mariner V Radio Occultation Experiments, Astron. J., 76, 123-140, 1971.

Folkins, I. and Martin, R. V.: The vertical structure of tropical convection, and its impact on the budgets of water vapor and ozone, J. Atmos. Sci., 62, 1560-1573, 2005.

Garcia, R. R. and Salby, M. L.: Transient response to localized episodic heating in the tropics. Part II: Far-field behavior, J. Atmos. Sci., 44, 499-530, 1987.

Gettelman, A. and Forster, P.: A climatology of the tropical tropopause layer, J. Meteorol. Soc. Jpn., 80, 911-924, 2002.

Healy, S. and Eyre, J.: Retrieving temperature, water vapour and surface pressure information from a refractive-index profiles derived by radio occultation: A simulation study, Q. J. Roy. Meteor. Soc., 126, 1661-1683, 2000.

Hunt, W. H., Winker, D. M., Vaughan, M. A., Powell, K. A., Lucker, P. L., and Weimer, C.: CALIPSO Lidar Description and Performance Assessment, J. Atmos. Ocean. Tech., 26, 1214-1228, doi:10.1175/2009JTECHA1223.1, 2009.

Jensen, E. J., Ackerman, S. A., and Smith, J. A.: Can overshooting convection dehydrate the tropical tropopause layer?, J. Geophys. Res., 112, D11209, doi:10.1029/2006JD007943, 2007.

Kley, D., Schmeltekopf, A. L., Kelly, K., Winkler, R. H., Thompson, T. L., and McFarland, M.: Transport of water through the tropical tropopause, Geophys. Res. Lett., 9, 617-620, 1982.

Kuo, Y.-H., Wee, T.-K., Sokolovskiy, S., Rocken, W., Schreiner, W., Hunt, H., and Anthes, R. A.: Inversion and Error Estimation of GPS Radio Occultation Data, J. Meteorol. Soc. Jpn., 82, 507531, 2004.

Kursinski, E. R., Hajj, G. A., Schofield, J. T., Linfield, R. P., and Hardy, K. R.: Observing Earth's atmosphere with radio occultation measurements using the Global Positioning System, J. Geophys. Res., 102, 23429-23465, 1997.

Kursinski, E. R., Hajj, G. A., Leroy, S. S., and Herman, B.: The GPS Radio Occultation Technique, Terr. Atmos. Ocean. Sci., 11, 53-114, 2000.

Pan, L. L., Bowman, K. P., Atlas, E. L., Wofsy, S. C., Zhang, F., Bresch, J. F., Ridley, B. A., Pittman, J. V., Homeyer, C. R., Romashkin, P., and Cooper, W. A.: The Stratosphere-Troposphere Analyses of Regional Transport 2008 (START08) Experiment, 
B. Am. Meteorol. Soc., 91, 327-342, 2010.

Randel, W. J. and Park, M.: Deep convective influence on the Asian summer monsoon anticyclone and associated tracer variability observed with Atmospheric Infrared Sounder (AIRS), J. Geophys. Res., 111, D12314, doi:10.1029/2005JD006490, 2006.

Randel, W. J. and Wu, F.: Kelvin wave variability near the equatorial tropopause observed in GPS radio occultation measurements, J. Geophys. Res., 110, D03102, doi:10.1029/2004JD005006, 2005.

Randel, W. J., Seidel, D. J., and Pan, L. L.: Observational characteristics of double tropopauses, J. Geophys. Res., 112, D07309, doi:10.1029/2006JD007904, 2007.

Rossow, W. B., Walker, A. W., Beuschel, D., and Roiter, M.: International Satellite Cloud Climatology Project (ISCCP) Description of New Cloud Datasets, WMO/TD-No. 737, World Climate Research Programme (ICSU and WMO), Geneva, 115 pp., 1996.

Schmidt, T., Beryerle, G., Heise, S., Wikert, J., and Rothacher, M.: A climatology of multiple tropopauses derived from GPS radio occultations with CHAMP and SAC-C, Geophys. Res. Lett., 33, L04808, doi:10.1029/2005GL024600, 2006
Sherwood, S. C., Horinouchi, T., and Zeleznik, H. A.: Convective impact on temperatures observed near the tropical tropopause, J. Atmos. Sci. 60, 1847-1856, 2003.

Sokolovskiy, S. V., Rocken, C., Lenschow, D. H., Kuo, Y.-H., Anthes, R. A., Schreiner, W. S., and Hunt, D. C.: Observing the moist troposphere with radio occultation signals from COSMIC, Geophys. Res. Lett., 34, L18802, doi:10.1029/2007GL030458, 2007.

Wang, P. K.: Moisture plumes above thunderstorm anvils and their contributions to cross tropopause transport of water vapor in midlatitudes, J. Geophys. Res., 108, 4194, doi:10.1029/2002JD002581, 2003.

Wickert, J., Reigber, C., Beyerle, G., König, R., Marquardt, C., Schmidt, T., Grundwaldt, L., Galas, R., Meehan, T. K., Melbourne, W. G., and Hocke, K.: Atmosphere sounding by GPS radio occultation: First results from CHAMP, Geophys. Res. Lett., 28, 3263-3266, 2001. 